\title{
Letters
}

Website: www.bmj.com

Email: letters@bmj.com

\section{Reducing the vertical transmission of HIV}

\section{Women should be tested at time of abortion}

EDITOR-The editorial by Mercey focuses on testing pregnant women attending antenatal clinics as the main means of reducing the vertical transmission of HIV. ${ }^{1}$ Most pregnant women seeking induced abortions would not have attended antenatal clinics.

In 1996, 167648 women aged 14 to 49 years had induced abortions. Goldberg et al found that HIV infection often occurs among women thought to be at low risk, and that those having terminations should be included when studying populations of pregnant women in areas of high prevalence. ${ }^{2}$ Birthistle et al showed that women who were seeking terminations-a high risk population-were not being tested in south west London, an area of high prevalence. ${ }^{3}$

Several studies have consistently found higher prevalence rates of HIV infection among pregnant women attending for termination than among those attending antenatal clinics. Rey et $\mathrm{al}^{4}$ reported that pregnant women who went on to deliver were more likely to have been tested for HIV during pregnancy than those who underwent elective abortion, yet women choosing abortion were more likely to engage in risky sexual behaviour than those continuing

Advice to authors
We prefer to receive all responses electronically,
sent either directly to our website or to the
editorial office as email or on a disk. Processing
your letter will be delayed unless it arrives in an
electronic form.
We are now posting all direct submissions to
our website within 72 hours of receipt and our
intention is to post all other electronic
submissions there as well. All responses will be
eligible for publication in the paper journal.
Responses should be under 400 words and
relate to articles published in the preceding
month. They should include 55 references, in the
Vancouver style, including one to the BMJ article
to which they relate. We welcome illustrations.
Please supply each author's current
appointment and full address, and a phone or
fax number or email address for the
corresponding author. We ask authors to declare
any conflicts of interest.
Letters will be edited and may be shortened.
www.bmj.com
letters@bmj.com

their pregnancy. The findings also suggested that pregnant women choose to be tested for HIV largely out of concern for the fetus.

Young single women constitute the fastest growing group of new cases of HIV infection. It follows that a young woman who tests positive for HIV at the time of requesting an abortion will be more likely to choose not to get pregnant again out of concern about having a baby who might be infected with the virus. However, a young woman having an abortion who is unaware that she is infected with HIV may get pregnant again and decide to continue her pregnancy. By the time she attends an antenatal clinic and is found to be infected with the virus, it may be too late to begin measures to prevent vertical transmission. If she had been tested when she had an abortion, effective preventive educational measures might have been instituted and she might have decided against getting pregnant again knowing the risk of vertical transmission.

Richardson and Sharland showed that, in many mothers, HIV infection is not detected until their child is 1 year old; by this time the mother may be pregnant again. ${ }^{5}$ This occurrence could be reduced if women were tested for HIV at the time of their abortion.

Babatunde A Gbolade Consultant gynaecologist St James's University Hospital, Leeds LS9 7TF

1 Mercey D. Antenatal HIV testing. BMJ 1998;316:241-2. (24 January.)

2 Goldberg DJ, Mackinnon H, Smith R, Patel NB, Scrimgeour JB, Inglis JM, et al. Prevalence of HIV among childbearing women and women having termination of pregnancy: multidisciplinary steering group study. BMJ pregnancy: multicisc

3 Birthistle K, Maguire H, Atkinson P, Carrington D. Who's having HIV tests? An audit of HIV test requests in a large London teaching hospital. Health Trends 1996;28:60-3. 4 Rey D, Moatti JP, Obadia Y, Rotily M, Dellamonica P, Gille JY, et al. Differences in HIV testing, knowledge and attitudes in pregnant women who deliver and those who terminate: Prevagest 1992-France. AIDS Care 1995;7:S3946.

5 Richardson MP, Sharland M. Late diagnosis of paediatric HIV infection in south west London. BMJ 1998;316:271-2. (24 January.)

\section{Pregnant women in Singapore support testing}

EdiTor-We share Mercey's view of the importance of testing pregnant women for infection with HIV. ${ }^{1}$ However, before implementing a screening programme for HIV among pregnant women it is important to determine the views of both the women and their healthcare providers

KK Women's and Children's Hospital is the main maternity hospital in Singapore and sees over 15000 births a year. In July 1997 we interviewed 106 consecutive antenatal patients in the hospital using a standard questionnaire. Women were asked their views on testing for HIV. They were given the facts about HIV infection and screening and told that, while confidentiality would be maintained as far as possible, HIV infection is a notifiable disease.

We surveyed $83(78 \%)$ Chinese, 17 (16\%) Malay, and six $(6 \%)$ women of other racial groups; this was a representative sample of the racial composition in Singapore. Altogether 89 (84\%) women indicated that they would want an HIV test if it were free, and 72 $(68 \%)$ would want it if it were charged at cost. A total of $95(90 \%)$ women agreed that the test should be offered to all pregnant women.

We also sent a structured questionnaire on antenatal testing for HIV to all 53 practising obstetricians in the hospital. Forty one $(77 \%)$ responded to the survey. Forty $(98 \%)$ of the obstetricians perceived the number of women infected with HIV in their practice to be low, one (2\%) to be moderate, and none perceived it to be high. Nevertheless, $23(56 \%)$ felt that HIV screening should be offered to all pregnant women, while 18 (44\%) felt that HIV screening should be offered only to those with risk factors for infection. Although 29 (71\%) obstetricians felt that antenatal HIV screening should be voluntary, 12 (29\%) felt that it should be mandatory.

The Singaporean government has taken a step towards encouraging antenatal HIV testing. In January 1998 the health ministry began charging only five Singapore dollars (£1.90) for HIV tests in primary care polyclinics, which is half the normal charge, to encourage more antenatal patients to be screened for HIV. These government polyclinics will also routinely offer the test, with appropriate counselling, to all women who attend for antenatal care.

The issue of whether to routinely test pregnant women for infection with HIV should not be decided based on cost effectiveness and prevalence rate, but must also take into account the views and opinions of women and the healthcare providers within their community.

K H Tan Consultant

K P Teo Consultant

Department of Maternal Fetal Medicine, KK

Women's and Children's Hospital, 100 Bukit Timah

Road, Singapore 229899 ktan@pacific.not.sg

1 Mercey D. Antenatal HIV testing. BMJ 1998;316:241-2. (24 January.) 
Department of Health should develop concise fact sheets about infection in pregnancy

EDITOR-The editorial by Mercey rightly emphasises the importance of testing pregnant women for infection with HIV. ${ }^{1}$ However, it was depressing to see the huge variation in the rates of testing in different centres. There is an urgent need for a standard fact sheet to be developed that can be given to all pregnant women. It could take the form of questions and answers covering topics such as the need for the test, the advantages of knowing whether the mother is infected, and the ways in which transmission to the baby can be reduced. Are such fact sheets given out in centres where large numbers of patients are tested? Fact sheets could form the basis for counselling pregnant women about the need for HIV testing.

It should not be necessary for every hospital to develop its own written information. The government health departments in Britain ought to take the lead in developing brief, comprehensible, and comprehensive information in English and other languages. This information could form the basis for brief counselling in general practice, where most of the initial blood samples are taken in early pregnancy. We need to be certain that all relevant information about HIV infection is discussed; one way of doing this is for health professionals to use high quality educational material to inform women of the need for HIV testing early in their pregnancy. If this material is already available we should know how to obtain it. If it does not currently exist, who should be responsible for its preparation and translation?

Ben Essex General practitioner

Sydenham Green Health Centre, London SE26 4TH

1 Mercy D. Antenatal HIV testing. BMJ 1998;316:241-2. (24 January.)

\section{More HIV training is needed for primary care staff}

EDITOR-Gibb and colleagues report the variable uptake of antenatal HIV testing in six maternity units in London. ${ }^{1}$ Increasingly, women with low risk pregnancies (which does not necessarily equate with low risk of HIV infection) are managed within primary care.

In 1992, I interviewed 151 women and 77 members of neighbourhood nursing teams in a London borough. Most of the women saw primary healthcare workers as their main professional source of advice and information on HIV. Two thirds of the healthcare workers reported contact through their work with people who were definitely or probably infected with HIV. Yet only $34 \%$ had received specific training on HIV related issues, and most of these felt that the training had been inadequate.

This highlights the need for a greater level of appropriate training in the community as well as in maternity units. This training is essential if universal information on and access to antenatal HIV testing, as advocated by Mercey, is ever to become a reality.

Mary A Waldron Research worker Belfast Healthy Cities Project, Belfast
1 Gibb DM, MacDonagh SE, Gupta R, Tookey PA, Peckham CS, Ades AE. Factors affecting uptake of antenatal HIV testing in London: results of a multicentre study. $B M$ 1998;316:259-61. (24 January.)

2 Mercey D. Antenatal HIV testing. BMJ 1998;316:241-2. (24 January.)

\section{Screening should not be restricted to} areas with high prevalence

EDITOR-The fact that much vertical transmission may be preventable has focused increasing attention on the availability of HIV testing at antenatal clinics. The seroprevalence of HIV infection in newborn babies of mothers in non-metropolitan England is $0.016 \%$ compared with $0.30 \%$ for newborns in inner London. ${ }^{1}$ In areas where the incidence of HIV infection is low 100000 mothers would have to be tested for HIV to find one positive result, and it has therefore been suggested that universal testing of mothers for HIV should not be adopted in provincial areas, where HIV infection is rarer.

In Portsmouth there are about 7000 deliveries a year. Women are sent information about the availability of HIV testing with their booking information, although whether testing is discussed depends on the individual midwife. In 1997 no pregnant woman was tested for HIV infection, although all women were routinely tested for syphilis and there was no positive result in this group. The inference from this is that no woman thought herself to be at risk of HIV infection. As a third of patients found to be HIV positive in the genitourinary medicine department over the past two years were from "low risk" groups, this is unlikely to be true. Half of these low risk patients were white women living in the United Kingdom who were not intravenous drug users or in any other risk groups for HIV infection. With a selective policy for screening, these women would not have been offered an HIV test had they been pregnant. The introduction of voluntary universal antenatal HIV testing has been proved to increase significantly the uptake of HIV testing. ${ }^{2}$ We believe that all pregnant women should be tested for HIV infection, including those at low risk. In this way all babies would have an equal chance of being protected from vertical transmission of HIV.

\section{Elizabeth Foley Specialist registrar}

V Harindra Consultant

Department Genitourinary Medicine, St Mary's Hospital, Portsmouth, Hants PO3 6AD

1 Nicoll A, McGarrigle C, Brady AR, Ades AK, Tookey P, Duong T, et al. Epidemiology and detection of HIVamong pregnant women in the United Kingdom: results from national surveillance 1988-96. BMJ 1998;316:253-8. (24 January.)

2 Mercey D, Helps BA, Copas A, Petruckvitch A, Johnson AM, Spencer J. Voluntary universal antenatal HIV testing. Br J Obstet Gynaecol 1996;103:1129-33.

\section{Women must be consulted}

EDITOR-Many of the authors in the issue on antenatal HIV testing on 24 January expressed varying degrees of frustration, mystification, and professional embarrassment at Britain's apparently uniquely low rate of HIV detection in pregnancy. Some seemed almost to suspect a conspiracy between subversive midwives and women with their own agenda to resist efforts to improve it.

The truth is, however, that women have not had much of an opportunity so far to contribute to the debate about how we might raise the uptake rate. None of the articles reported any input from community representatives other than as survey respondents, for example. The Maternity Alliance and the Terrence Higgins Trust were invited to participate as user liaison advisers to the intercollegiate working party drawing up guidelines on HIV testing in pregnancy, after the first draft had been prepared. We hosted a consultation meeting around the guidelines with half a dozen maternity and community groups representing African families affected by HIV and AIDS in London. Those who came were critical of the way HIV is handled generally in many maternity units, but in particular they had little confidence that current services were always sufficiently confidential, supportive of those testing positive, or culturally sensitive. The working party has not addressed their anxieties, however, as it has concentrated on promoting the principle of antenatal HIV testing. Subsequent discussions with community groups have since revealed a wide disparity in views about the best way to proceed and even some hostilities about what little consultation there has been.

It is clear that significant progress will not occur until those directly affected are able to contribute properly to the development of policies and to strategies for their implementation. This won't be quick or easy given the many vested interests involved and the need to allay suspicions. The present campaign must move beyond a focus on diagnosis targets to include the experiences and views of the pregnant women who will have to make the choice whether to be tested-and live with the consequences.

Meg Goodman Health policy officer Maternity Alliance, London EC2P 2LX

\section{Screening programme has not failed}

Editor-The articles in the 24 January issue about antenatal screening for HIV all agreed that the test is performing badly at identifying women infected with HIV. However, we feel that the situation is not as gloomy as it has been portrayed.

The Department of Health guidelines promoting voluntary HIV testing for pregnant women were published in $1994 .{ }^{1}$ Unfortunately, there were no specific guidelines for healthcare staff to implement an HIV screening policy, and very little funding was provided. It was largely left to each unit to design and introduce its own HIV screening programme. This meant that testing was mainly left to midwives with variable training and among whom staff turnover is often high. Programmes developed haphazardly throughout the country, particularly in areas of high HIV prevalence. In addition, HIV testing was, until recently, perceived by many as a complex test which takes time and 
is rarely done outside genitourinary medicine clinics. Targeting funding at obstetricians might have led to a greater involvement of those responsible for antenatal care, resulting in the earlier introduction of more widespread antenatal testing.

The conclusions drawn from this review of the HIV antenatal screening programmes in the United Kingdom could have been more positive. Firstly, there is no doubt that most obstetricians have now accepted the value of antenatal testing ${ }^{23}$ and to describe them as indifferent ${ }^{4}$ is, in most cases, unfair.

Secondly, it has been established that those at greatest risk of a given disease are least likely to show a high uptake of screening procedures, particularly when the disease is associated with poverty - "the inverse care law." ${ }^{5}$ This may, in part, explain the poor uptake of HIV testing among African women. A similar situation existed with cervical screening, in which it has taken at least 10 years to improve coverage.

Finally, while there was, appropriately, a great deal of discussion about the outcome of babies born to an HIV infected mother, little was said about the equally important issue of the effect of a positive result on the woman and her relationships. Yet this must be the most important factor influencing a woman's decision to have a test.

We commend the authors for their thorough audit into antenatal HIV screening but feel it is premature to conclude that the screening programme has failed.

Adeola Olaitan Specialist registrar Department of Obstetrics and Gynaecology

Sara Madge General practice fellow, HIV medicine Melvyn Jones Lecturer in general practice Margaret Johnson Director of HIV and AIDS Services

Royal Free Hospital, London NW3 2QG

1 Department of Health. Guidelines for offering voluntary named HIV antibody testing to women receiving antenatal care. named HIV antibody testing to women receic 2 Smith JR, Barton SE, Boag FC, Steer PJ. Antenatal testing for HIV: to opt in or opt out,

Gynaecol 1996;103:1059-60.
3 Johnstone FD. HIV and pregnancy Br J Obstet Gynaecol 1996;103:1184-90

4 Mercey D Antenatal HIV testing BMJ 1998;316:241. (24 January.

5 Tudor Hart J. The inverse care law. Lancet 1971:i:405-12.

\section{Italian obstetricians often don't ask} women to take test

EDITOR-The studies by Jones et al and Gibb et al underline the fact that the acceptability of antenatal HIV testing depends on the health providers who offer the test. ${ }^{12}$ Part of this effect can be explained by different attitudes of health providers towards testing. In addition, obstetricians and midwives need to recognise the importance of universal antenatal HIV testing. We surveyed the attitudes of Italian obstetricians toward antenatal HIV testing. In Italy women with normal pregnancies are cared for by obstetricians and not midwives.

We identified 66 obstetrics centres affiliated to the Association of Italian Gynaecologists and Obstetricians. These centres were not formally representative of Italian obstetrics centres, but they were well distributed in the main areas of the country: 50 were in northern and central Italy, 16 in southern Italy and the islands.

A postal questionnaire was sent to 752 doctors in charge of the centres. We posted a reminder to non-responders after two months. A total of 419 (55.7\%) returned completed questionnaires to the coordinating centre, $280(37.2 \%)$ after the first mailing and $139(18.5 \%)$ after the second. Of the 419 respondents (median age 43 years, range 29-67), 306 were men (54.8\% of the 558 questionnaires sent to men) and 113 were women $(58.2 \%$ of 194 questionnaires sent to women).

Obstetricians were directly asked about the need for routine antenatal HIV screening. Most $(87 \%)$ thought that a routine antenatal HIV test was needed. However, only $52 \%$ always ask women to take it, $16.5 \%$ often ask, and $28.1 \%$ ask only women at risk $3.4 \%$ never ask women to take it. Nearly all of the obstetricians $(95.3 \%)$ stated that women do not refuse to be tested.

These data suggest that in Italy a large proportion of obstetricians do not in practice agree with routine testing of all women for HIV before or during pregnancy and that women generally accept the HIV test. This last finding is consistent with the results of a previous study showing that only $12 \%$ of pregnant women objected to their blood being tested for HIV infection. ${ }^{3}$

In order to obtain higher rates of antenatal HIV testing we believe that educational campaigns should be focused on obstetricians more than on women.

Fabio Parazzini Chief of epidemiological unit

Elena Ricci Research fellow

Paola Grasso Research fellow

Matteo Surace Clinical fellow

Istituto di Ricerche Farmacologiche "Mario Negri," Milano, Italy

Guido Benzi Assistant professor

Prima Clinica Ostetrico Ginecologica, Università di Milano, Milano, Italy

\section{Jones S, Sadler T, Low N, Blott M, Welch J. Does uptake of antenatal HIV testing depend on the individual midwife? Cross sectional study. BMJ 1998;316:272-3. (24 January.) \\ 2 Gibb DM, MacDonagh SE, Gupta R, Tookey PA, Peckham Gibb DM, MacDonagh SE, Gupta R, Tookey PA, Peckham
CS, Ades AK. Factors affecting uptake of antenatal HIV CS, Ades AK. Factors affecting uptake of antenatal HIV esting in London: results of 1998:316:259-61. (24 January.) \\ 3 Parazzini F, Cavalieri D’Oro L, Bortolus R, Dindelli M, Mar F, Manfe M. Attitudes of pregnant women toward routine human immunodeficiency virus antibody testing in Italy. Acquir Immune Defic Syndr 1993;6:635-6.}

\section{Anonymous testing is unethical}

EDITOR-Anonymous antenatal testing for HIV is still carried out in many centres in the United Kingdom despite clear evidence since 1992 that avoiding breast feeding significantly reduces vertical transmission of HIV and, since 1994, that perinatal treatment with zidovudine has an even greater effect. Only the editorial ${ }^{1}$ in the $B M /$ s special edition on antenatal testing for HIV considered the ethics of testing pregnant women anonymously.

Any blood taken from patients is assumed to be for tests which will be of benefit to them, unless stated otherwise. With anonymisation, health professionals are placed in a position whereby they cannot perform their duty of care to a patient by offering advice or treatment if the test result is positive. Anonymisation should not be assumed to absolve health professionals from their duty of care. This ethical blinkering threatens abandonment of patients. ${ }^{2}$

The correlative right of a patient to have her best interests preserved may be waived if proper informed consent is given. Nevertheless, after 1992, and even 1994, many women providing blood for unlinked HIV testing were not informed of the benefits and burdens of receiving the result despite the fact that they had a strong interest in receiving this information. For example, the leaflet published by the Department of Health and the Central Office of Information (issued in 1989, but still circulated after 1992) did not refer to breast feeding or to treatments available. These women cannot be said to have given truly informed consent

Can it be ethical for health professionals to collude in depriving a child-to-be the increased opportunity to escape a fatal disease, even if women give informed consent? Public policy, I submit, should deny a patient the opportunity to waive her doctor's duty to her when this creates a risk to the lives of third parties-even if these are not "legal persons."

The prevalence studies are governed by a utilitarian ethic which discounts the importance of respecting women's autonomy. It also underestimates the benefits of women being informed of their HIV status. The Department of Health now advises routine voluntary named HIV testing in areas of high prevalence. ${ }^{3}$ Why is anonymous testing (especially in these areas) not condemned and discontinued?

Paquita de Zulueta Lecturer in general practice Department of General Practice and Primary Care, St Mary's Campus, Imperial College School of Medicine, London W2 IPG

\footnotetext{
1 Mercey D. Antenatal HIV testing. BMJ 1998;316:241-2. (24 January.)

2 Grubb A, Pearl DS. Blood testing, AIDS and DNA profiling. Law and policy. Bristol: Family Law, Jordan and Sons, 1990:24-7

3 Department of Health. Guidelines for offering voluntary named HIV antibody testing to women receizing antenatal care. London: DoH, 1994.
}

\section{Late diagnosis of HIV infection} in children causes distress

EdiToR-Richardson and Sharland expressed concern that Department of Health guidelines on antenatal testing have had no effect on the method of presentation of paediatric HIV infection. ${ }^{1}$ We share their concern that late presentation continues to deprive children of the benefits of timely treatment, parental education, and social support, and, on the basis of our research, would add a further reason for wishing to reduce the number of late presentations: the additional distress caused to families when HIV infection is first identified in an ill child.

We conducted in depth interviews with parents or guardians of 22 of the 35 surviving HIV infected children seen in the paedi- 
atric department of St Mary's Hospital to the end of December 1994. Twenty one children had been infected through vertical transmission. In most families the child was the first person to have HIV infection diagnosed, usually after becoming acutely ill and being admitted to the local district general hospital. Parents were devastated when they were told and still remembered it as a particularly distressing experience. They reported that HIV infection was rarely raised as a possible diagnosis before tests were carried out and that they were not at all prepared for a diagnosis of HIV infection.

Antenatal testing would increase the detection rate of HIV infection among pregnant women and reduce the number of children who were diagnosed when ill. It is particularly difficult for families to cope with the diagnosis of HIV infection in their child, and the implications this may have for other members of the family, at a time when their child is seriously ill. ${ }^{2}$ Antenatal care provides an opportunity to offer testing before a crisis arises as part of a planned programme provided by professionals with suitable experience and the facilities for follow up support and advice.

Mary Boulton Senior lecturer

David Miller Emeritus professor

Eddy Beck Senior lecturer

Department of Epidemiology and Public Health,

Imperial College School of Medicine, London W2 IPG

Sam Walters, Senior lecturer

Department of Paediatrics, Imperial College School of Medicine

1 Richardson MP, Sharland M. Late diagnosis of paediatric HIV infection in south west London. BMJ 1998;316:271-2. (24 January.)

2 Evans JA, Marriage SC, Walters MDS, Levin M Unsuspected HIV infection presenting in the first year of life. BMJ 1995;310:1235-6.

\section{Risk of breast cancer is also increased among retired US female airline cabin attendants}

EDITOR-An excess incidence of breast cancer has been reported among Finnish ${ }^{1}$ and Danish $^{2}$ airline cabin attendants (standardised incidence ratio $1.9(95 \%$ confidence interval 1.2 to 2.2 ) and 1.6 (0.9 to 2.7) respectively). In a retrospective cohort survey of retired flight attendants from one US airline we also found an excess incidence of breast cancer (standardised incidence ratio $=2.0$ (1.0 to 4.3)) (unpublished data).

Neither of the previous reports identified a cause for this excess incidence. One suggested that, on the basis of estimated exposures, radiation could account for an excess incidence of only $10 \% .{ }^{1}$ Another study said that radiation could be responsible for the excess by acting as a cancer promoter but provided little corroborating evidence. ${ }^{3}$

We suggest that exposure to dicophane (DDT), an organochlorine pesticide used to rid airplanes of insects in the 1950 s to 1970 s, may be a risk factor for breast cancer. According to a recommendation by the World Health Organisation, on certain international flights DDT was to be sprayed throughout the aircraft from a single use, hand operated aerosol dispenser by a flight attendant after the doors were closed before takeoff, while air ventilation was limited. This may have resulted in substantial inhalation and dermal exposure to DDT for the person operating the aerosol.

Several population based studies have investigated DDT as a risk factor for breast cancer and obtained mixed results. ${ }^{4}$ Using a case-cohort analysis we assessed whether flight attendants with high exposures to DDT might be more likely to have breast cancer. For comparison we assessed whether those who had made more flights in their career-a proxy for exposure to cosmic radiation-might be more likely to have breast cancer. We asked the flight attendants to tabulate by year the number of flights on which they flew and the number of flights on which they sprayed pesticides. Those with breast cancer were more likely to have had higher than median exposures to DDT than those without breast cancer (odds ratio 2.2 (0.4 to 10.9)). A much weaker and slightly protective association was found between breast cancer and number of flights flown (odds ratio 0.8 (0.2 to 3.5)). Although other risk factors for breast cancer were not adjusted for, the effect size of these confounders in other studies is insufficient to explain the excess we observed.

Our preliminary data are consistent with previously reported excess incidences of breast cancer among flight attendants. Furthermore, they support the hypothesis that exposure to DDT may be a risk factor for breast cancer. More carefully designed studies are needed to resolve these unusual and consistent findings.

Daniel Wartenberg Associate professor Cecile Pryor Stapleton Doctoral student Environmental Health Division, Environmental and Occupational Health Sciences Institute, Piscataway, NJ 08855-1179, USA

1 Pukkala E, Auvinen A, Wahlberg G. Incidence of cance among Finnish airline cabin attendants, 1967-92. BM/ 1995;:311:649-52.

2 Lynge E. Risk of breast cancer is also increased amon Danish female airline cabin attendants. BMJ 1996:312:253. 3 Stewart T, Stewart N. Breast cancer in female flight attendants. Lancet 1995;346:1379.

4 Hunter DI, Hankinson SE, Laden F, Colditz GA, Manson JAE, Willett WC, et al. Plasma organochlorine levels and the risk of breast cancer. New Engl J Med 1997;337:1253-8.

\section{Intractable problems need long term solutions, not quick fixes}

EDITOR-Sometimes it is difficult to be pleased about progress. The new green paper Our Healthier Nation represents progress. For the first time, a government has made an unequivocal statement about the importance of socioeconomic factors for health. Previous governments have been reluctant to acknowledge that poverty kills or that poor housing makes people ill, and any problem cannot begin to be solved until it is acknowledged.

The government clearly wants to tackle the root causes of health inequalities-such as social exclusion-but the green paper also recognises that problems that have been part of the fabric of society for as long as health inequalities have been are unlikely to be amenable to short term solutions. Our Healthier Nation is therefore an important and honest step in the right direction.

In spite of this many public health practitioners experienced dismay on reading the green paper because it does not contain any targets for reducing inequalities in health. There are targets for reducing overall death rates from the "big killers" and exhortations that progress on these should not be achieved just by improving the health of the better off. There are, however, no targets for reducing the gap in mortality between rich and poor. Instead the government recommends that targets for reducing inequalities should be set at local level. Social inequalities are evident in local health statistics but, because of the smaller number of deaths involved, local statistics will be much less sensitive to small increases or decreases.

The absence of such targets raises concerns about the government's commitment to succeed. The previous government showed that national policy can impact on social inequalities by increasing them, ${ }^{1}$ so there is every reason to suppose that this government's policies could be effective in reducing them. Do ministers not really believe that they will succeed or do they not really want to?

The elimination of health inequalities represents a major challenge and will not be achieved by a single government paper. It is likely, however, that the proposals in the green paper will begin to reverse the current trend. If they fail to do so or if they continue to drive it in the wrong direction it is important for everyone to know early on so that the proposals can be rethought. We need to believe that the government is committed to trying, not that it will necessarily succeed the first time. Setting targets for reducing inequalities in death rates and including them in the final white paper would ensure that confidence.

Sarah Stewart-Brown Director

Health Services Research Unit, Department of Public Health, Institute of Health Sciences, University of Oxford, Oxford OX3 7LF

Sian Griffiths Director of public health and health policy

Oxfordshire Health Authority, Oxford OX3 7LG

1 Wilkinson RG. Unhealthy societies: the affliction of inequality. London: Routledge, 1996.

\section{Copper is unlikely to cause contact allergy}

EDITOR-In their article on diagnosing allergy Rusznak and Davies give copper as a common example of contact allergy. ${ }^{1}$ However, copper has an extremely low sensitising potential. During the 16 years from 1960 to 1976 only one case of copper sensitivity 
was seen at St John's Institute of Dermatology; this occurred in a woman whose hobby was copper beating. ${ }^{2}$ Copper salts are irritants, and patch testing with high concentrations may give misleading results. On the other hand, cobalt is a well documented sensitising agent, ${ }^{3}$ and maybe it was to this that the authors meant to refer.

Andrew Morris Research fellow

John English Consultant

Department of Dermatology, Queen's Medica

Centre, University Hospital, Nottingham NG7 2UH

1 Rusznak C, Davies RJ. ABC of allergies: diagnosing allergy. BMJ 1998;316:686-9.

2 Cronin E. Contact dermatitis. Edinburgh: Churchill Livingstone, 1980:326-8.

3 Burrows D, Adams RM. Metals. In: Adams RM, ed. Occupational skin disease. 2nd ed. Philadelphia: Saunders, 1990:349-86.

\section{Topical chloramphenicol is an outmoded treatment}

EDITOR-A recent issue of the BMI contained two articles on chloramphenicol eye drops and their association with haematological toxicity. ${ }^{12}$ Lancaster et al detected three patients with serious haematological toxicity who had used the eye drops (one of whom died). ${ }^{1}$ These cases, in addition to the 23 already reported in the national register of drug induced ocular side effects (in Oregon, United States),, are too many when other safe, equally efficacious, economically rational preparations are available.

Ophthalmic practitioners in the United States do not use chloramphenicol eye drops for this very reason. It is rare to see such a contrast in clinical practice between the United States and the United Kingdom. Wiholm et al report that of over 400 patients with aplastic anaemia noted, none had used chloramphenicol eye drops, ${ }^{2}$ but this does not answer the clinical question of whether chloramphenicol eye drops cause haematological toxicity. Aplastic anaemia is but one end of the haematological spectrum. The way forward for this therapeutic dilemma lies with a randomised, prospective study, but such a study is unlikely ever to be undertaken. Therefore case reports are at present our only source of information. To date there are 26 reported cases of marrow suppression associated with ocular chloramphenicol.

In our opinion topical chloramphenicol is an outmoded treatment with serious though small risks. Our American colleagues have got it right, and we would do well to follow their example.

M Doona Registrar

J B Walsh Consultant physician

Department of Medicine for the Elderly, St James's Hospital, Dublin 8

1 Lancaster T, Swart AM, Jick H. Risk of serious haematological toxicity with use of chloramphenicol eye drops in a British general practice database. $B M J$ 1998;316:667. (28 February.)

2 Wiholm B, Kelly JP, Kaufman D, Issaragrisil S, Levy M, Anderson T, et al. Relation of aplastic anaemia to use of chloramphenicol eve drops in two international casecontrol studies. BMJ 1998;316:666. (28 February.)

3 Doona M, Walsh JB. Use of chloramphenicol as topical eye medication: time to cry halt? BMJ 1995;310:1217-8.

\section{Screening for prostate cancer}

\section{Key studies have only just started}

EDITOR-Whelan is correct in stating that "there is no turning the clock back" to the era of the management of prostate cancer before testing for prostate specific antigen was available. ${ }^{1}$ It is a pity, however, that he is so negative about the antigen, which has stimulated an enormous amount of research into prostate cancer since its discovery.

Good evidence shows that prostate cancer is not always as indolent as suggested. The best available population based cohort study of conservative management shows that men with moderately differentiated tumours (three quarters of the tumours) lose 4-5 years of life and those with poorly differentiated tumours lose $6-8$ years of life. ${ }^{2}$ In addition, Whelan himself admits that half of men dying of prostate cancer are under 75 and a considerable proportion are under 65 . The description of prostate cancer as a "homely" disease does not square with the observations of most practitioners who look after patients dying of metastatic prostate cancer.

We would all be delighted to base our actions on the results of randomised controlled trials, but we are dealing with new molecular technology and the key studies are only just under way. ${ }^{3}$ For the individual patient, the potentially false reassurance that prostate cancer is a non-progressive disease is not evidence based. An increasing body of evidence shows that tumours detected by measurement of prostate specific antigen, far from being unimportant well differentiated tumours, are predominantly moderately differentiated (Gleason score 5-7), which are being diagnosed at an earlier, and therefore curable, stage. ${ }^{4}$ In the absence of evidence from randomised controlled trials, general practitioners and urologists need to present the putative pros and cons of having the prostate specific antigen test, and the potential advantages and disadvantages of radical treatment, and allow informed patients to decide for themselves whether they wish to be investigated.

D Hrouda Specialist registrar

J H Davies Consultant

Department of Urology, Royal Surrey County Hospital, Guildford, Surrey GU2 5XX

R S Kirby Consultant

Department of Urology, St George's Hospital,

London SW17 0QT

1 Whelan P. Are we promoting stress and anxiety? BMJ 1997;315:1549-60. (6 December)

2 Albertson PC, Fryback DG, Storer BE, Kolon TF, Fine J. Long-term survival among men with conservatively treated localized prostate cancer. JAMA 1995;274:626-31.

3 Schroder FH, Bangma CH. The European randomized study of screening for prostate cancer (ERSPC). Br J Urol study of screening for

4 Newcomer LM, Stanford JL, Blumenstein BA, Brawer MK 4 Newcomer LM, Stanford JL, Blumenstein BA, Brawer MK dence of advanced stage disease, 1974 to 1994 . J Uro 1997;158:1427-30.

\section{Detecting and extirpating premetastatic tumours seems a legitimate objective}

EDITOR-Most people will not die of cancer, and in most types of cancer surgery the results are suboptimal, but this does not excuse the therapeutic nihilism shown by Whelan in his Personal View on screening for prostate cancer. ${ }^{1}$ A similar type of pessimism was formerly fashionable in the United Kingdom with regard to breast carcinoma and is now discredited. Detecting and extirpating a tumour in a premetastatic stage seems a legitimate objective.

Data indicate that screening men in their early 50 s for prostate specific antigen is a sensitive and specific method of detecting progressive tumours (which are now the third commonest cause of death from cancer in men). ${ }^{2}$ There are good series relating tumour grade and stage to survival, so to establish the value of screening it would be necessary to show only that the tumours detected are at an earlier stage than those presenting symptomatically.

Clearly, imaging methods are insufficiently accurate and need improvement. The possibility already exists of carrying out cryosurgery or laser surgery of the lesions with simultaneous magnetic resonance imaging, and this seems likely to provide an alternative to radical prostatectomy, free of the more serious side effects.

I would be interested to know what proportion of doctors with prostate cancer who have appraised the literature and have not yet reached the age of 70 would opt for watchful waiting. For those of us who have acquired carcinomas in our 50s to pay a doctor to watch us die does not seem a good investment.

David J Evans Professor of histopathology Imperial College School of Medicine, St Mary's Hospital, London W2 1PG

1 Whelan P. Are we promoting stress and anxiety? BMJ 1997;315:1449. (6 December.)

2 Foulkes W. Detection of prostate cancer. BMJ 1995;310:1139-40.

\section{Surgery lengthens survival}

EDITOR-I presume that Whelan was having a joke in decrying the ability to identify a marker for cancer. ${ }^{1}$ Measurement of prostate specific antigen might not be perfect, but, as he said, it is better than what went before, even though ignorance is bliss.

The US Congress has just agreed with the concept of screening for colorectal cancer, which occurs in 150000 Americans each year. Why bother? Why not let the colonic polyps develop as they used to? We could then ignore the results until the patient presented with carcinomatosis. But that is not acceptable. When I remove a colon carcinoma I do not kid myself that I am curing all my patients. But I do cure some, and for the others I buy some time, measured perhaps as a grandchild or a wedding.

In the days before prostate specific antigen was known about my father in law presented with backache and was eventually found to have metastatic prostate cancer. He was about 60 . His stress and anxiety level was high as he struggled to live to 65 so that his wife would have a decent pension. He died when he was 64 . He did see his daughter marry me, but did not see his grandchildren. 
Not surprisingly, my wife wanted me to have my prostate specific antigen measured. When I was 57 I could not ignore the high number any more. Stress and anxiety crept in when the results of prostatic biopsies were positive. After the radical prostatectomy my urologist said that with watchful waiting I would have been dead in three years but that my survival rate was now $90 \%$. I prefer those odds. I never had a subliminal desire to have a male disease, because I intended to go on forever, but to do this I recognised that some screening was inevitable. I also knew that the earlier a cancer is diagnosed the easier it is to treat and the better the results obtained.

I am aware that one school of thought suggests that earlier diagnosis has no impact on the outcome of cancer and that the "extra" survival time is the same as it would have been if the disease had been diagnosed later; this suggests that treatment at any time during the disease has no effect whatsoever. But Walsh and Brooks pointed out that Sweden had the fourth highest age adjusted mortality from prostate cancer in the world, with a $21 \%$ higher death rate from prostate cancer than the United States. ${ }^{2}$ On the basis of one prospective randomised trial, much criticised, can we really not treat early prostate cancer?

W B Hodgson Professor of surgery, cell biology, and anatomy

New York Medical College, Valhalla, NY10595, USA

1 Whelan PC. Are we promoting stress and anxiety? BMJ 1997;315:1549-50. (6 December.)

2 Walsh PC, Brooks JD. The Swedish prostate cancer paradox. JAMA 1997;277:497-8.

\section{Why can't the clock be turned back?}

EDITOR-Whelan performs a good hatchet job on the prostate specific antigen test but draws back from a logical conclusion by writing, "There is no turning the clock back." Why? If, as he says, prostate specific antigen testing merely promotes stress and anxiety why is the test still widely done? (Since my wife and I have recently been through a period of extreme stress and anxiety induced by prostate specific antigen testing we can testify to the reality of the phenomenon.) How many lives does prostate specific antigen testing save? Has it, in fact, ever saved a life? How many doctors have their prostate specific antigen measured regularly? Men with obstructive symptoms seem to be no more at risk of prostate cancer than those without symptoms, ${ }^{2}$ so the common practice of measuring their prostate specific antigen seems to have little scientific basis. Until the evidence is available to support routine prostate specific antigen testing why not turn the clock back and stop doing it? Whelan points out that the emperor is scantily clad; like the courtiers of old he refuses to go the whole hog.

D P Addy Retired paediatrician

15 Dyott Road, Moseley, Birmingham B13 9QZ

1 Whelan P. Are we promoting stress and anxiety? $B M J$ 1997;315:1549-50. (6 December.)

2 Catalona WJ, Richie JP, Ahmann FR, Hudson MA, Scardino PT, Flanigan RC et al. Comparison of digital rectal examination and serum prostate specific antigen in the tal exary detection of prostate cancer: results of a early detection of prostate cancer: results of a multicentical trial of 6630 men. J Urol 1994;151:1283-90.
clinical

\section{The use or uselessness of annual public health reports}

\section{Response from author of report}

EDITOR-I scarcely recognise my paper Reporting the Public Health from reading Scally's editorial. ${ }^{2}$ I do not argue for centralisation of funding, merely that the budget for the production and dissemination of annual reports should be administered, and thereby ring fenced as a protected public health function, by the minister for public health. This could elevate the exercise in those authorities where it has often been done on the cheap with little attention to impact. It would also prevent any further merging of annual public health reports with those of health authorities. In other words, it would safeguard their independence.

Scally is therefore wrong to suggest that the net effect of several of my recommendations would be to reduce the independence of the public health report. The whole thrust of my report is towards a more independent public health function. In arguing for reorganisation of the public health infrastructure (with some prescience, as it turns out) I propose a distinct pyramidal structure independent of the NHS Executive whose "ethos would be one of independence to monitor and publicly criticise not only Department of Health policies, as implemented by health authorities, but any area of policy which has a bearing on health."

In commenting on the least substantial of my recommendations (that the reports could be published every two or three years instead of annually) Scally suggests that there is no shortage of public health issues to be tackled and that annual reports can and should be a catalyst to action. That is my point exactly. I propose low cost annual statistical updates and two or three yearly in depth reports yielding a minimum set of comparable data relevant to national policy initiatives, such as a strategy to tackle health inequalities. This is far from being the "greater government specification of content" which Scally sees as constraining. It would simply enable annual reports to be a tool for monitoring progress towards agreed targets appropriate to local populations. Directors of public health should be free to report on any issue they consider relevant to the public health, and I also propose designating the director of public health with the lead role in developing local, multisectoral strategies for health.

Ann Davies Associate researcher

Institute for Public Policy Research, London WC2E 7RA

1 Davies A. Reporting the public health: a new role for annual public health reports. London: Institute for Public Policy Research, 1997.

2 Scally G. The use or uselessness of annual public health reports. BMJ 1997;315:1173-4. (8 November)
Producing independent annual reports would be career suicide for directors of public health

EDIToR-I have yet to meet anyone (other than students at community colleges) who has read a director of public health's annual report; I myself haven't-and I have contributed to several. I suspect that they remain unread because are boring. They lack useful new ideas and critical comment. Therefore, I commend Scally for raising the issue of their effectiveness. ${ }^{1}$ These reports are ineffective because Scally's statement that "directors are well placed ... to produce independent reports on the local population's health" is just not true. This is not surprising since it would be career suicide for a director to produce an independent report.

A director of public health is accountable to the district health authority's chief executive. Understandably, only a doctor sympathetic to-some might say sycophantic to-the health authority's views will be appointed as director. Once appointed, this director spends his or her time supporting the health authority's activities. Not surprisingly, he or she does not have the knowledge to produce an informed report on nonNHS issues. Sadly, there is no evidence that directors use their intimate knowledge of the functioning of the health authority to produce independent reports concerning the NHS activities. For instance:

- During the past eight years there surely must have been at least one health authority that wasted the odd $£ 100000$. I have yet to read a report discussing such an event.

- Many people believe that block contracts between health authorities and NHS trusts are inappropriate. Where are the reports that advise alternatives?

- Hospital acquired infections are a major health issue. There is a powerful case to be made for a health authority insisting that all elective "clean" surgery is performed on premises and by staff who do not treat high risk infected patients - that is, not in existing trust hospitals. I have not read discussions of this or similar issues in a director's report.

If directors' reports are to be effective the independence of directors of public health must be restored and they must stop acting as NHS managers. A start could be made by moving departments of public health medicine out of district health authority premises.

A Rouse Acting consultant in public health medicine Somerset Health Authority, Taunton TA1 2DN

1 Scally G. The use or uselessness of annual public health reports. BMJ 1997;315:1173-4. (8 November)

\section{Treating Helicobacter pylori infection after surgery is unnecessary}

EDITOR-We read with interest the systematic review by Danesh and colleagues of the prevalence of infection with Helicobacter pylori among patients after surgery. ${ }^{1}$ The 
overall prevalence of $H$ pylori infection after partial gastrectomy was $50 \%$ and after vagotomy was $83 \%$. This finding is consistent with our study in which infection with $H$ pylori was found in 36 out of 73 $(49 \%)$ patients after gastrectomy and 13 out of $20(65 \%)$ after vagotomy. ${ }^{2}$ However, the authors' recommendation that these patients should be reviewed and considered for treatment with antibiotics is questionable.

Studies have failed to find an increase in the rate of ulcer relapse after gastric surgery in patients infected with $\mathrm{H}$ pylori. ${ }^{23}{ }^{4}$ Other factors such as bile reflux and the use of non-steroidal anti-inflammatory drugs could also account for the recurrence of ulcers. Recurrent ulceration occurs in $10-20 \%$ of cases after proximal gastric vagotomy and in less than $5 \%$ after subtotal gastrectomy. ${ }^{5}$ There is no evidence to suggest that curing $H$ pylori infection would reduce the incidence of ulcers occurring after gastric surgery. Routine screening for $H$ pylori would subject patients to expensive and unnecessary investigations. Furthermore, indiscriminate use of antibiotics not only wastes resources but also increases the risk of adverse drug reactions and resistance to antibiotics.

Y T Lee Registrar

Francis K L Chan Associate professor

Joseph J Y Sung Professor

Department of Medicine and Therapeutics, Prince of Wales Hospital, Shatin, NT, Hong Kong

1 Danesh J, Appleby P, Peto R. How often does surgery for peptic ulceration eradicate Helicobacter pylori? Systematic review of 36 studies. BMJ 1998;316:746-7. (7 March.)

2 Lee YT, Sung JJY, Choi CL, Chan FKL, Ng EKW, Ching YL, et al. Ulcer recurrence after gastric surgery: is Helicobacter pylori the culprit? Am J Gastroenterol (in press).

3 Ludtke FE, Maierhof S, Kohler H, Bauer FE, Tegeler R, Schauer A, et al. Helicobacter pylori colonization in surgical patients. Chirurg 1991;62:932-8.

4 Svoboda P, Krpensky A, Munzova H, Kunovska M. Helicobacter pylori after proximal selective vagotomy. Vnitr Leh 1991:37:772-5.

5 Matthews JB, Silen W. Operations for peptic ulcer disease and early postoperative complications. In: Sleisenger MH Fordtran JS, eds. Gastrointestinal disease. 5th ed. Philadelphia: Saunders, 1993.

\section{WMA urges national medical associations to ensure that economic sanctions respect agreed exemptions}

EDITOR-Redgrave and Waller raised the important issue of the effect of economic sanctions on the health and nutrition of the Cuban population. ${ }^{1}$ The report from the American Association for World Health on the impact of the United States' embargo was brought to the attention of the international committee of the BMA shortly after its publication in March 1997. ${ }^{2}$ As a result of the concerns raised by the whole issue, the matter was taken by the BMA to the council of the World Medical Association in Paris in April last year. After consultation with other national medical associations the BMA submitted a resolution on economic embargoes on health, which was passed unanimously at the 49th general assembly of the World Medical Association in Hamburg, Germany, in November 1997. The succinct resolution states:

"Recognising that all people have the right to the preservation of health and that the Geneva Convention (article 23, No IV 1949) requires the free passage of medical supplies intended for civilians, the WMA urges national medical associations to ensure that governments employing economic sanctions against other states respect the agreed exemptions for medicines, medical supplies, and basic food items."

Since then, as chairman of the medical ethics committee of the World Medical Association, I have been in correspondence with the UK Foreign and Commonwealth Office. Recently the minister of state, Tony Lloyd, has written to me agreeing that "the humanitarian impact of sanctions should be carefully considered before they are imposed and that trade sanctions should include humanitarian exemptions to allow the supply of food and medicines. This should be the case whether the sanctions are imposed by the United Nations, or by any other organisation." The foreign secretary, Robin Cook, has called for a humanitarian meeting on Iraq to ensure that the issues that the BMA has mentioned are fully considered.

The problems are clearly more widespread than the avoidable tragedies that the people of Cuba are having to face. The BMA will continue its campaign, and at the next meeting of the World Medical Association in Ottawa this October I will be discussing the BMA's experience with other national medical associations and seeking progress reports from them.

James Appleyard Chairman, medical ethics committee, World Medical Association BMA, London WC1H 9JP

1 Redgrave P, Waller J. BMA must voice its opposition to Cuban embargo. BMJ 1998;316:1248. (18 April.)

2 American Association for World Health. Denial of food and medicine: the impact of the US embargo on health and nutrition in Cuba. Washington, DC: AAWH, 1997.

\section{Clinical trials should be designed to include elderly people}

Editor-G Bugeja et al have shown that elderly people tend to be excluded from clinical research, ${ }^{1}$ a fact we can support from our own experience. We searched Medline for all articles that contained the word "elderly" in the title or abstract, and combined the results of this search with all titles mapped under the heading "randomised controlled trials" that were published between January 1966 and July 1996. This search yielded only 150 articles. We excluded 89 because they were not actual randomised controlled trials - that is, they were reviews, letters, or not trials of drug treatment. Of the 61 remaining, 50 articles dealt specifically with elderly people, the main subjects being hypertension (13 papers), neuropsychiatry (11), and cardiology $(7){ }^{2}$
Despite this very poor return, there may be legitimate reasons why elderly people are excluded from randomised controlled trials, and although the authors of the articles we identified mention a few reasons they make no suggestions as to how we might redress this issue. Perhaps the two main reasons for the reluctance of researchers to involve elderly people in clinical trials of drugs are that both multiple pathology and treatment with multiple drugs are common in the elderly population. The worry from the trial organisers' perspective is that interference from symptoms arising from concurrent disease or intercurrent illnesses may introduce bias and thus make the interpretation of adverse events more difficult. Treatment with multiple drugs may add to this interference, especially when there is concern about drug interactions and poor compliance.

We believe that protocols should be specifically designed to account for comorbidity and treatment with multiple drugs. Compliance with protocols could be improved by involving pharmacists in counselling patients about the drug under investigation, and perhaps even in visiting patients at home. Indeed the involvement of other support workers to coordinate the visits and investigations should be encouraged given the greater supervision necessary to ensure the accuracy of such trials in elderly people.

It is important that we have sufficient information to be able to use drugs appropriately in elderly people, and that they should have the opportunity of benefiting from advances in medical knowledge and treatment. We need to educate our elderly patients, our medical colleagues, and the public about the importance of including elderly patients in clinical research. However, more specifically, we suggest that paying more attention to the design of clinical trials of drugs could improve the reliability of the information yielded and provide a more practical approach to studying drug treatment in elderly people. Inevitably more financial resources will be necessary to achieve this goal.

Jacqueline Bene Clinical research fellow Richard Liston Clinical research fellow University Department of Geriatric Medicine, Clinical Sciences Building, Hope Hospital, Salford M6 8HD

1 Bugeja G, Kumar A, Banerjee AK. Exclusion of elderly people from clinical research: a descriptive study of people rom clinical research: a descriptive study
published reports. BMJ 1997;315:1059. (25 October) 2 Bene J, Liston R. The special problems of conducting clincal trials in elderly patients. Rev Clin Gerontol 1997;7:1-3.

\section{Why clinical audit doesn't work \\ Education and debate $\mathrm{p} 1893$}

\section{Clinical audit in nursing homes has} proved ineffective

EditoR-We share Berger's frustration with clinical audit in its current form. ${ }^{1}$ Between 1995 and 1997 we tried to introduce clinical audit into nursing homes in Wakefield. There are 24 registered homes with nearly 1000 beds-equivalent to an entire hospital-and their quality of care has 
obvious and lasting relevance to the quality of life for residents.

The project coordinator (JC) introduced the concept of clinical audit to local homes, provided training, and helped each home conduct an audit of its own choosing. One home refused to participate. The other 23 were receptive, but in five no progress was made because of staff changes. Eleven topics were audited by 15 homes; the other three conducted pseudo-audits that were actually management activities, such as stock control.

The 11 topics were: reporting of accidents; procedures of staff changeover; continence care, activities and stimulation of residents (3 homes); individual keyworker system, where each resident has a named worker on their case; compliance with safety standards in the workplace; quality of laundry; planning of food and menus (2 homes); ordering and planning of drug treatments; moving and handling; and quality of written care plans (2 homes). A year after they began, most of these audits remained incomplete, and only three are likely to have brought about improvements that are perceptible to residents. These are small benefits for the effort and resources invested, and we are pessimistic about auditing topics that may be on the health authority's agenda but that homes are reluctant to address.

We are aware of 16 audit exercises in UK nursing homes (3 from peer reviewed sources). These suggest that clinical audit may have more success if it is combined with both external leverage (such as the cycle of registration and inspection) and an internal product champion (such as an enthusiastic matron). Even then, it is a weak lever for quality improvement in the face of so many pressures. Many homes are struggling to cope with dependent residents, staff shortages, and financial difficulties. It is unrealistic to expect clinical audit in isolation to change this climate.

Yet if we were to go back to first principles and design an ideal mechanism for quality assurance for nursing homes or any other health unit, it would look uncannily similar to audit. It would be adequately funded, be professionally led, set explicit standards, involve regular review, and so on. This suggests that we should not despair of audit but confront the forces that impair quality.

Graham C Sutton Senior clinical lecture Nuffield Institute for Health, Leeds LS2 9PL

Jayne Collingwood Nurse audit project coordinator Wakefield and Pontefract Community Health NHS Trust, Castleford Health Centre, Castleford WF10 5LT

Keith Pattison Project manager Wakefield WF2 7EB

Mike Walker Nursing home adviser Wakefield Health Authority, Wakefield WF1 1LT

1 Berger A. Why doesn't audit work? BMJ 1998;316:875-6. (21 March.)

\section{Monitoring undermines confidence in} medical services

EDITOR-According to Berger's editorial, more money and effort are to be applied to revitalising official audit. ${ }^{1}$ Authorities should admit that the enterprise has failed to deliver an improvement in patient care that is commensurate with the cost.

Unfortunately, the decision to cut one's losses means an unacceptable loss of face. The apathy and the passive resistance on the part of clinicians to the implementation of the imposed audit procedures are an indication not that they lack interest in improving their performance but that they do not find them relevant to the everyday business of keeping things going. It can prove rather tedious to sit down once a month or so to listen to a presentation by another specialty of a study that deals with only a tiny part of that specialty's problems when there are more pressing difficulties closer to home

It seems that major initiatives such as audit and continuing medical education can be introduced without the stringent requirements that are required-for example, when a new treatment is being evaluated. This "cognitive dissonance" is quite demoralising and leads to a cynicism and distrust of the authorities-for example, the colleges that endorse these measures. When audit did not achieve an early resolution of the difficulties that a Bristol hospital had with paediatric cardiac surgery it was surely time to admit that it was failing to do what it was supposed to do. This failure is a consequence of a flaw far more fundamental than differences of opinion between managers and clinicians, as the NHS Executive seems to believe.

"Systematic" audit as commended can deal with only small areas of practice. As a result the topics that are being investigated are often peripheral to the concerns of a functioning clinical team. This makes the effort involved in conducting an audit seem an exercise in academic methodology, with long delayed and minuscule rewards. Meanwhile, the real problems of suboptimal performance receive less attention.

Audit was introduced on the assumptions that our practice was imperfect, that it would be demonstrably improved by inspection procedures, and that this would allay the increasing public unease about what doctors are doing about monitoring their performance for audit. The last two assumptions have not been realised, and the first will never be corrected. No regulatory institutions-for example, an engineered "Ofmed"-can replace intrinsic professionalism. The distrust that is implicit in the manoeuvering of our colleges in this field by imposing more and more untried and unproved monitoring is undermining confidence in their members as well as in the laity. I believe that these attempts at regulation are misguided and their failure ought to be admitted.

G H Hall Chief medical officer Medical Sickness Society, Exeter EX2 5SP

1 Berger A. Why doesn't audit work? BMJ 1998;316:875-6 (21 March.)

\section{Success depends on type of audit}

EDITOR-Berger's editorial asks "Why doesn't audit work?" I have recently contributed a chapter on audit and conflict to a book on the subject, ${ }^{2}$ and I would like to try to provide some answers to this question using psychoanalytical ideas.

Clinical audit is rightly identified as a cycle of setting standards, monitoring performance, and then implementing change to bring performance up to standard. The lack of impact of research and of clinical audit on clinical practice contrasts with the concept of evidence based practice. It is also crucial, however, that we seek evidence that is practice based, stemming from our everyday clinical work.

Participation in the audit cycle usually involves people in important and personally meaningful activities. The setting of standards, if we set them ourselves, is not usually problematic. However, standards that are set for us by others may be actively or passively opposed. It is also easier to observe and measure performance if we actively participate ourselves in developing and implementing measures. We can feel quite paranoid if our performance is monitored by outsiders using their own measures and performance indicators. Taking the necessary steps to implement change can often prove an impossible task. Many of us prefer to hold on to the status quo, to the familiar, and to the known.

I have distinguished two types of audit. The first I have termed "ego driven audit." This is based on work group mentality, is task orientated, ${ }^{3}$ and is driven by an active curiosity. The second type, the "superego driven audit," is a process rife with basic assumptions and is usually done in an unthinking way at the behest of others. It is this second type of audit that most obviously does not work; and it rarely leads to effective ownership of the process and change in practice as a result.

Kevin Healy Director

Cassel Hospital, Richmond, Surrey TW10 7JF

1 Berger, A. Why doesn't audit work? BMJ 1998;316:875-6. (21 March.)

2 Patrick M, Davenhill R. Rethinking clinical audit. London: Routledge, 1998.

3 Obholzer, A, Roberts, VG. The unconscious at work: individual and organisational stress in the human services. London: Routledge, 1994.

\section{Profession must rise to challenge of innovation}

EDITOR-Berger asserts that audit has failed to deliver change and needs to be revitalised. ${ }^{1}$ We believe that the limitations of clinical audit have become apparent and that the place of audit in quality improvement programmes needs to be reconsidered.

Berger outlines a key limitation: clinical audit has not been integrated into a wider organisational agenda so that its outputs have often not been acted upon. Even if this were the case, however, integrated audit alone cannot optimise practice. Factors such as allocation of resources, quality of training, configuration of service, and development 
of effective patterns of care have separate contributions to make.

Furthermore, the principle of professional self audit that has prevailed to date raises the question of whether audit failed or whether we as professionals failed to deliver audit. Noticeable numbers of clinicians have not attempted systematically to audit their practice. Although the ethos of personal responsibly for competent clinical performance is essential, it is not necessary that this process is undertaken behind closed doors. As professionals we must expect scrutiny. If this scrutiny is fair and unbiased it is something we should welcome, not resist.

The NHS white paper, with its emphasis on clinical quality, gives us the greatest opportunity in the history of the NHS to seize the initiative and really improve the quality of all NHS services. The challenge now is to bring together the many differing approaches that we have for quality improvement and make them work together. Clinical audit, the clinical effectiveness initiative, risk management, and organisational audits-for example, the King's Fund and ISO 2000-will all contribute to better services. Responsibility at board level or clinical governance should help us focus.

As professionals, however, we must embrace the challenge. If our commitment and active participation are not forthcoming we will be justifiably criticised. That is not to say we should accept responsibility for any shortcomings of the service that are beyond our power to resolve.

Our ambition should be systematic quality improvement in all aspects of the service. This will not happen overnight. We all feel the pressures of delivering the service day to day, but we all have to find the energy to address quality improvement. The process will be hard and frustrating at times. If progress is slow it will not do to blame one another. The vitality that we need is for improving quality, and clinical audit has an important part to play, but it will not deliver all the answers.

John Woodhouse Director of public health Russell Gorton Consultant in public health medicine County Durham Health Authority, Durham DH1 5XZ

Berger A. Why doesn't audit work? BMJ 1998;316:875-6 (21 March.)

\section{Having electronic preprints is logical}

EDITOR-Delamothe asks what the policy of journals should be on publication on the internet of electronic preprints ("eprints"). ${ }^{1}$ He points out that some journals, including the New England Journal of Medicine and, currently, the $B M J$, reject papers whose substance has already appeared as an eprint because they regard this manoeuvre as prior publication. This policy is illogical and impossible to police. What is the difference between the published abstract of a study presented at a conference and an eprint?
The only differences are that the internet version is more accessible and likely to be a fuller account of the study. To enforce the restrictive policy journals must even now be searching the internet for evidence of prior publication of every paper they receive; we do not envy them this nightmare.

We can imagine a scenario in which journals offer a home for eprints. When authors have ready a draft of a paper they could ask for the eprint to appear on a journal's website. Those papers that survive the in house selection procedure (about a third in The Lancet's case) would appear on the website within a few days of submission, accompanied by a note of the expected date of submission of the "definitive" draft and, as Delamothe suggests, a request not to quote the study. Once the paper had gone through the formal peer review process the eprint would be removed from the web and its fate (including, for an accepted paper, a link to the definitive published version) recorded in the eprint archive.

And what of papers that have appeared as eprints on non-journal websites? Editors who support the eprint policy could not logically refuse to consider these papers on their own merits when formally submitted. The disadvantage of this system for authors, as Bingham has pointed out, is that they would not be able to submit rejected papers to journals that opposed the eprint policy. ${ }^{2}$

The system outlined above should work for the bulk of medical research that interests only other medical researchers. An issue that requires careful consideration, however, is whether journals should host the eprints of studies whose results have the potential to cause real public concern. If the answer to this is yes, will the eprint be viewable by everyone or will there be controlled access? Perhaps the authors of such contentious studies can be encouraged to work with editors, reviewers, and public health agencies at the earliest stage of manuscrip preparation to ensure that publication is swift and quality assured.

John McConnell Multimedia editor

Richard Horton Editor

The Lancet, London WC1B 3SL

1 Delamothe T. Electronic preprints: what should the BM] do? BMJ 1998;316:794-5. (3 March.)

2 Bingham C. Peer review on the internet: a better class of conservation. Lancet 1998;351(suppl 1):S10-4.

\section{Education still needs to be improved for trainee doctors}

EDITOR-Two recent editorials have brought back to the fore the debate about the need for improvements in the training of junior doctors and why temporal fortitude in terms of years spent working in service based posts gaining "experience" is not a surrogate for truly structured training. ${ }^{12}$

It was agreed by all signatories to the heads of agreement in 1990 that all basic and most higher specialist training needs could be fulfilled within duty limits of 72 hours as laid down in the new deal. ${ }^{3}$ At that time shift systems were introduced to reduce continuous duty periods for juniors working in high intensity specialties, thus protecting patients from overtired doctors. The BMA's Junior Doctors Committee has long argued that it is poor organisation of training around reductions in hours that has been detrimental, not the reductions in hours themselves. In 1993 the Calman report recommended the introduction of structured training programmes for higher specialist training, coupled with competency based assessments. ${ }^{4}$ All royal colleges agreed that this was necessary and feasible and that such training could still be provided within the hours limits, yet the provision of structured training programmes in many specialties is still awaited.

We accept that consultant expansion is urgently needed, not only to train the specialists of the future but for the current exigencies of service needs; yet this may not be the only reason that structured training programmes are not being delivered. There is too much reliance on service provided by trainees, service that cannot be regarded as training as it is unsupervised and often unskilled. We wish to see the emphasis of the training of this country's doctors redirected to concentrate on modern principles of adult learning. A set of monthly lectures for specialist registrars is inadequate.

Postgraduate training, along with all other training and learning, needs to be learner centred, modular, and service based yet not service reliant. The concepts of appraisal and mentoring for trainees must be grasped. The objective of competence and its assessment needs to be developed. Educational agreements between the trainee, trainer, postgraduate dean, and trust are still rare, yet were recommended in the original "orange guide." If all these provisions were in place there would be little argument that limiting hours of work or introducing shift patterns of work was detrimental to training. At the heart of Rosborough's argument is a combination of a limited workload and "excellent formal education." In the United Kingdom we supposedly have the former-the new deal; it is about time we had the latter.

Trevor Pickersgill Deputy chairperson (education and training)

Mark Porter Chairperson

Andrew Hobart Deputy chairperson (hours of work and medical staffing)

Nizam Mamode Deputy chairperson (negotiating) Junior Doctors Committee, BMA, London WC1H 9JP

1 Roberton DM. Shifts in opportunities for doctors in training. $B M J$ 1998;316:1032-3. (4 April.)

2 Rosborough TK. Doctors in training: wasteful and inefficient? BMJ 1998;316:1107-8. (11 April.)

3 NHS Management Executive. Junior doctors-the new deal. London: Department of Health, 1991.

4 Department of Health. Hospital doctors: training for the future. London: DoH, 1993

5 NHS Executive. A guide to specialist registrar training. London: Department of Health, 1996. 